\title{
The Relationship of the Deviant Workplace Behavior with the Organizational Justice and Staff Development in the Universities of Tehran
}

\author{
Mohsen Rafiee, PHD student, university of Isfahan \\ Reza Hoveida ${ }^{1}$, Assistant Professor, University of Isfahan \\ Saeid Rajaeipoor, Associate Professor, University of Isfahan
}

Doi:10.5296/ijhrs.v5i1.7075 URL: http://dx.doi.org/10.5296/ijhrs.v5i1.7075

\begin{abstract}
The present study aims at investigating the relationship of the deviant workplace behavior with the organizational justice and staff development in the universities of Tehran. The descriptive-correlational research method has been used, while the data analysis has relied on the correlation and regression analysis. The research population has comprised of the all staff of the selected universities in Tehran. Sampling has been conducted through stratified random method, which resulted in a sample with 326 participants. In order to measure the deviant workplace behavior and staff development, two researcher-made questionnaires have been used (reliability $=0.92$ and 0.85 , respectively), while the organizational justice has been measured using the Niehoff and Moorman (1996) (reliability=0.87). The findings revealed that deviant workplace behavior has a negative relationship with the staff development $(\mathrm{p}=32)$ and organizational justice $(\mathrm{p}=22$ ). The results of the regression analysis delineated that staff development has a mediating role in the relationship between organizational justice and deviant workplace behavior. That is, organizational justice sets grounds for staff development and in turn, staff development reduces the deviant workplace behaviors.
\end{abstract}

Keywords: Deviant Workplace Behavior, Staff Development, Organizational Justice, University Staff

\section{Introduction}

The escalating rate of detrimental and harmful organizational behaviors during recent years has absorbed numerous researchers and theoreticians. Researchers' serious note of suchlike behaviors has been due to their increasing prevalence as well as the considerable expenses that are consequently imposed on the organizations. The spectrum of the negative and harmful behaviors has been referred to through terms like deceit, destructive work, lying, and vilification. Those behaviors that threaten the organization through violation of the rules are referred to as deviant workplace behaviors. Deviant workplace behavior can be simply defined as a purposeful behavior that violates the norms of an organization and threaten the health of the organization and its staff. This behavior is purposeful, because the staff doesn't

\footnotetext{
${ }^{1}$ Corresponding author(r.hoveida@edu.ui.ac.ir)
} 
have any motivation to adapt to the norm expectations or they might be motivated to breach those expectations (Maccardli, 2007). However, it cannot be said that any behavior that breaches a norm is deviant. Here, the criterion is threatening the organization (Salmani \& Radmand, 2009). From Bennett and Robinson's (1997) viewpoint, deviant workplace behavior includes behaviors that are conducted by a faction of colleagues to violate the common norms of the organization. Through his research projects, Greenberg (1998) has identified six groups of negative workplace behaviors that include workplace deviance, antisocial behaviors, organizational aggression, retaliatory behavior, organizational misbehavior, and organization-motivated aggression. Although deviant workplace behaviors have been categorized in numerous ways, but the most well-known categorization (Litinzi \&kimberli, 2006, as cited in Salmani \& Radmand, 2009) has divided such behaviors into four groups. First, production deviance occurs when the staff violates the quality and quantity standards and cause increased production expenses or reduced quality of the products. Second, political deviance happens when the staff supports a certain group or faction and exposes the whole organization to a set of harms. Third, property deviance includes waste or theft of the property through accounting documents. Finally, personal aggression includes hostility and aggressive behaviors toward others.

Following their efforts to identify the underlying factors of the foregoing behaviors, David and Adler (2008) have considered the personal, group, leadership, and organizational factors as the underlying factors of the deviant workplace behavior in organizations. From the viewpoint of Bennett and Robinson (2003), organizational justice is an important variable in predicting the deviant behaviors. Moorman (1991) defines organizational justice as the methods used to treat the staff in a way that they feel they are being treated fairly. Research on the organizational justice has been conducted during the past four decades and different theories have been proposed in this regard. Almost all of them state that organizational justice can be evaluated through distributive, procedural, and interactional justice (McCardle, 2007).

Distributive justice refers to the consideration that distribution of the outcomes of the organization's activities should be just, so that every individual can achieve their just favorable share according to their contribution, efforts, and capabilities. Procedural justice is taken to mean that the process of individuals achieving just results should be just itself. That is, individuals don't have the right and should not be able to attain just results through adoption of unjust processes. Interactional justice emphasizes that individuals' all interactions and interrelationships in the process of achieving the just results should be just themselves. In other words, individuals don't have the right to go through unjust interactions with others in their way toward attaining just goals (Purezzat \& Gholipur, 2009).

Another variable that has been found by some studies as effective on the occurrence of deviant workplace behaviors is the staff development. Mackenzie et al (2012) have shown that staff development leads to reduction of deviant and ineffective behaviors on the organizational level, and conversely, lack of staff development is one of the main reasons in an organization's staff inclination toward ineffective and deviant behaviors. Moreover, Georji and Jozef (2003) have suggested that the staff development programs in organizations significantly affect the employees' behaviors in the workplace (as cited in Golparvar and Nadali, 2011). Staff development is a program that motivates the staff and guides them to 
develop their skills, and enhances their capabilities according to a constant program (Lipow \& Carver, 1994). Staff development is a set of activities that improves staff's knowledge, skills, and attitude so they can successfully perform their present duties and be prepared to take future responsibilities.

In staff development, results are more important than methods, and the status of the staff in the organization is taken into account (Noe, 2008). Achieving the learning opportunities, cooperating with colleagues to attain the vocational goals, creating effective learning environment, trying to evaluate oneself, scrutinizing the changes and providing feedback, and taking part in seminars and workshops are considered as the staff development factors (Shahpasand et al, 2006).

From Raymond Noe's (2008) viewpoint, there are four approaches for staff development, including formal training, evaluation, job experiences, and interpersonal relationships. Formal training or courses includes programs in and out of the workplace which have been devised specifically for the organizational staff and is held by academic consultants or instructors as short term courses. Evaluation includes collecting data and providing feedback for the staff on their behaviors, methods of building relationships, values, or skills. Job experiences refer to relationships, necessities, duties, and other dimensions of the workplace that the staff usually confronts. The staff can improve their knowledge and skills regarding the organization and its customers through interaction with their more experienced colleagues. Mentoring and tutoring are two interpersonal relationships that are used in staff development.

Radmand and Salmani's (2009) study reveals that the presence of injustice in paying back for the services, injustice in law enforcement, and cultural weakness can be identified as the effective factors in staff's inclination toward deviant behaviors. McCardle (2007) showed that organizational injustice and centralism are among the main factors that lead to deviant behaviors. In other words, organizational justice and centralism are good predictors of deviant behaviors. Ineo et al (2010) conducted a research project on the organizational justice, psychological pressures, and vocational commitment in Japanese workers. They found out that procedural justice and interactional justice were significantly related and had negative relationships with the psychological pressure and at the same time, enjoyed positive relationships with vocational commitment. In mediation analysis, carrier reward was found to be a significant mediator of procedural commitment with the interactional and vocational commitments. Findings of McKenzie et al (2012) on the effect of staff development on reduction of ineffective and detrimental behaviors have delineated that staff development simultaneously affects staff's ineffective individual, organizational, and social behaviors. Staff development programs - which are usually designed and conducted to improve the organizational behavior - influence the organizational behaviors as well as social and individual behaviors, and reduce the ineffective and detrimental behaviors at individual, organizational, and social levels. Similar results have been obtained in Radmand and Salmani (2009) and Golparvar et al (2011). By performing ten strategies for empowerment of the high school staff and teachers, Lampers (2004) found out that professional improvement of school teachers and staff improves their skills, helps them build effective interrelationships, and reduces deviant behaviors. Aroocas and Kamless (2008) conducted a research on the performance model of job processes and staff's inclination to 
leave the job. They concluded that job enrichment strategies have a positive relationship with staff commitment and a negative relationship with inclination to leave the job. In order to identify the causes of deviant behaviors occurrence, Appelbaum (2007) tried to answer two questions. First, why people commit deviant behaviors? Second, why organizations allow such individuals to commit these behaviors? The results of their study revealed that the management and organization's behaviors on one side, and staff's lack of professional growth on the other side are the main causes that make individuals commit deviant behaviors, and if there is no fault and shortcoming in the organization's system, there will be no grounds for the occurrence of the deviant behaviors.

Since universities are considered as educational systems, they have an important mission to educate and train the youth in a society. The harms caused by the deviant behavior occurrence in these systems is twofold. First, such behaviors reduces efficiency and efficacy of the system and impedes the organization to achieve is goals and mission (Ferris, Brown, \& Heller, 2009). Second, occurrence of the deviant behaviors in universities causes cultural harms and. On the other hand, today nearly four million Iranians are university students (Asr Iran, 2013), and the university environment directly and remarkably affects the lives of this population. Therefore, it seems necessary to conduct research projects in universities to establish grounds for specification, prediction, and controlling of such behaviors.

To evaluate the previous related research projects, it might be noted that those studies have not clearly concentrated on the relationship of the deviant workplace behavior with staff development and organizational justice, and the university environment has not been the target population of these studies. Therefore, according to the foregoing discussions, we intend to answer the following questions in this study. First, is there any relationship between deviant behaviors and staff development? Second, is there any relationship between deviant behaviors and organizational justice? Third, if the pattern of the relationship of the deviant workplace behavior with organizational justice and staff development is fitting?

Research methodology

The research methodology in this study has been descriptive-correlational. The research population is comprised of the staff of all selected state universities in Tehran, including the University of Tehran (1080 individuals), Shahid Beheshti University (590 individuals), Allameh Tabatabaee University (435 individuals), Sharif University of Technology (483 individuals) and Iran University of Medical Sciences (643 individuals). This list entails two comprehensive universities (Tehran and Shahid Beheshti universities), a university devoted to Humanities (Allameh Tabatabaee University), a technical university (Sharif University of Technology), and a medical university (Iran University of Medical Sciences). All in all, the research population is comprised of 3231 individuals.

Sampling method was that of stratified random sampling with appropriate distributions. The sample size (346) was specified based on Morgan's table. Then, according to the total staff of each university, the participants were selected, including 116 individuals from the University of Tehran, 63 individuals from Shahid Beheshti University, 47 individuals from Allameh Tabatabaee University, 52 individuals from Sharif University of Technology, and 69 individuals from Iran University of Medical Sciences. As noted above, a total of 346 participants were selected randomly. 


\section{Instruments}

In order to collect the deviant workplace behavior data, a researcher-made questionnaire of deviant behavior was used which had been devised specifically for educational environments. This questionnaire entails 32 items, which based on the Bennett and Robinson's (1995) categorization, measured four categories of procedural, financial, political, and interpersonal deviant behaviors. The questionnaire was piloted with participation of 30 staff of Shahid Beheshti University. The results of factor analysis confirmed the questionnaire factors categorization. Finally, in order to assure the reliability of the questionnaire and internal consistency of the questions, the Cronbach's Alpha index was calculated for the pilot sample (30 individuals). The obtained Alpha value ( $\mathrm{r}=0.92)$ revealed the reliability of the questionnaire and internal consistency of its items.

In order to collect organizational justice data, Niehoff and Moorman's (1996) questionnaire was used which has been evaluated by No'ami and Shokrkon (2002). This questionnaire entails three subscales of distributive, interactional, and procedural justice, presented through 20 items. The Cronbach's Alpha index for this questionnaire is 0.87 . However, in order to assure the compatibility of this questionnaire with the present research population, it was piloted in the population. The confirmatory factor analysis results verified the organizational justice questionnaire subscales. Moreover, the obtained 0.92 Cronbach's Alpha index shows the high level of reliability.

In order to collect data on staff development, a researcher-made questionnaire was used which was devised based on Noe's (2008) and Pursadeq's (2005) theoretical models of staff development. This questionnaire was consisted of six factors. More specifically, education, team work, organizational skill, development of the carrier path, development of interpersonal relationships, and communications are the six factors of staff development.

To assure the compatibility of the questionnaire with the present research population, the questionnaire was piloted in the population. The results of the confirmatory factor analysis revealed that some questions did not match the subscales. Consequently, some minor corrections were made in the questionnaire, so a reliability value of 0.85 was attained.

The obtained data was analyzed through descriptive, correlational, and regression analysis techniques and was fed into the Structural Equation Modeling (SEM). SEM is a method of multivariate analysis of correlation. This method is the most suitable data analysis method for the quantitative section of the present study, since SEM can be used in the analysis and evaluation of the theoretical models (Schumacker \& Lomax, 2009).

Findings

\section{A) Descriptive Findings}

In this section, a description of the research variables is provided. To do so, first the contextual variables, and then, the research variable are describe. However, it should be noted that the overall number of participants whose data is used for the analysis is 295 . Out of these, 32.5 percent work at the Universtiy of Tehran, 15.3 percent at the Sharif University of Technology, 20.3 percent at the Iran University of Medical Sciences, 17.3 percent in Shahid Beheshti University, and 14.6 percent in Allameh Tabatabaee University. Besides, 18 percent of the participants have one to five years of job experience, nearly 32 percent have five to ten years of job experience, nearly 31 percent have 10 to 15 years of job experience, more than 


\section{Macrothink $\Delta$ Institute ${ }^{\text {tm }}$}

12 percent have 15 to 20 years of job experience, and more than seven percent have more than 20 years of job experience. Moreover, most of the respondents had an undergraduate degree (46.2 percent), while nearly six percent had a high school diploma, nearly 22 percent were associates, nearly 24 percent had a graduate degree, and more than two percent had a $\mathrm{PhD}$ degree.

Deviant workplace behavior

Based on the obtained results, the deviant workplace behavior rate of more than 73 percent of the participants has been low, 26.5 percent medium, and around 0.3 percent has been high.

Table (1) distribution Frequency of deviant work behavior

\begin{tabular}{|r||l|l|l|l|l|l|l||}
\hline Tniversity & $\begin{array}{r}\text { Tehran } \\
\text { university }\end{array}$ & $\begin{array}{r}\text { Sharif } \\
\text { university }\end{array}$ & $\begin{array}{r}\text { medical } \\
\text { science } \\
\text { University } \\
\text { wehavio }\end{array}$ & $\begin{array}{r}\text { Beheshti } \\
\text { university }\end{array}$ & $\begin{array}{r}\text { Allame } \\
\text { university }\end{array}$ & number & persent \\
\hline \hline Not at all & 77.1 & 60 & 3.3 & 27.5 & 51.2 & 139 & 47.1 \\
\hline Not much & 8.3 & 22.2 & 58.3 & 31.4 & 18.6 & 77 & 26.1 \\
\hline \hline Usually & 14.6 & 17.8 & 38.3 & 39.2 & 30.2 & 78 & 26.5 \\
\hline Somewhat & 0 & 0 & 0 & 2 & 0 & 1 & 0.3 \\
\hline Very & 0 & 0 & 0 & 0 & 0 & 0 & 0 \\
much & 100 & 100 & 100 & 100 & 100 & 295 & 100 \\
\hline \hline Total & 100 & & & & & \\
\hline
\end{tabular}

Organizational justice

The concept of organizational justice has been grasped through 20 questionnaire items, as the following table illustrates. The conceptual orientation of the items has relied on concepts like distributive, procedural, and interactional justice. Combining the foregoing items in one scale, it is revealed that 27.5 percent of the respondents have seen the organizational justice in their workplace to be low, more than 42 percent of them have remarked it to be medium, and more than 30 percent of the participants have noted organizational justice in their workplace to be high.

Table (2) distribution Frequency of organizational justice

\begin{tabular}{|r|r|r|r|r|r|r||r||}
\hline $\begin{array}{r}\text { University } \\
\text { Organizational } \\
\text { justice }\end{array}$ & $\begin{array}{r}\text { Tehran } \\
\text { university }\end{array}$ & $\begin{array}{r}\text { Sharif } \\
\text { university }\end{array}$ & $\begin{array}{r}\text { medical } \\
\text { science } \\
\text { University }\end{array}$ & $\begin{array}{r}\text { Beheshti } \\
\text { university }\end{array}$ & $\begin{array}{r}\text { Allame } \\
\text { university }\end{array}$ & \multicolumn{2}{|c|}{ total } \\
\hline Not at all & 0 & 8.9 & 11.7 & 2 & 2.3 & 13 & 4.4 \\
\hline Not much & 27.1 & 17.8 & 40 & 5.9 & 16.3 & 68 & 23.1 \\
\hline Usually & 29.2 & 40 & 41.7 & 66.7 & 46.5 & 125 & 42.4 \\
\hline Somewhat & 43.8 & 26.7 & 6.7 & 19.6 & 27.9 & 80 & 27.1 \\
\hline Very much & 0 & 6.7 & 0 & 5.9 & 7 & 9 & 3.1 \\
\hline \hline Total & 100 & 100 & 100 & 100 & 100 & 295 & 100 \\
\hline \hline
\end{tabular}

Staff development 
The concept of staff development has been grasped through 30 questionnaire items. The conceptual orientation of the items has relied on concepts like training improvement, team work, organizational skills, carrier path, interpersonal relationships, and communications. Combining the foregoing items in one scale, it is revealed that nearly 17 percent of the participants have seen the staff development in their workplace to be weak, nearly 59 percent of them have remarked it to be medium, and more than 24 percent of the participants have noted staff development in their workplace to be strong.

Table (3) distribution Frequency of staff development

\begin{tabular}{|c|c|c|c|c|c|c|c|}
\hline \multirow{2}{*}{ University } & \multirow{2}{*}{$\begin{array}{r}\text { Tehran } \\
\text { university }\end{array}$} & \multirow{2}{*}{$\begin{array}{r}\text { Sharif } \\
\text { university }\end{array}$} & \multirow{2}{*}{$\begin{array}{r}\text { medical } \\
\text { science } \\
\text { University }\end{array}$} & \multirow{2}{*}{$\begin{array}{r}\text { Beheshti } \\
\text { university }\end{array}$} & \multirow{2}{*}{$\begin{array}{r}\text { Allame } \\
\text { university }\end{array}$} & \multicolumn{2}{|r|}{ total } \\
\hline & & & & & & number & $\overline{\text { persent }}$ \\
\hline Not at all & 0 & 0 & 1.7 & 0 & 0 & 1 & 0.3 \\
\hline Not much & 10.4 & 11.1 & 51.7 & 2 & 4.7 & 49 & 16.6 \\
\hline Usually & 63.5 & 53.3 & 45 & 62.3 & 67.4 & 173 & 58.6 \\
\hline Somewhat & 26 & 28.9 & 1.7 & 20.9 & 20.9 & 61 & 20.7 \\
\hline Very much & 0 & 6.7 & 0 & 7 & 7 & 11 & 3.7 \\
\hline Total & 100 & 100 & 100 & 100 & 100 & 295 & 100 \\
\hline
\end{tabular}

B) Findings related to the research questions

Question 1: Is there any significant relationship between deviant workplace behaviors and organizational justice?

Table (4) correlation between organizational justice and deviant work behavior

\begin{tabular}{|c|ll|l|l|}
\hline \multicolumn{5}{||c|}{ Deviant work behavior } \\
\hline \hline $\begin{array}{c}\text { Organizational } \\
\text { justice }\end{array}$ & $\begin{array}{l}\text { Pierson } \\
\text { value }\end{array}$ & $\mathrm{R}^{2}$ & $\mathrm{sig}$ \\
\cline { 2 - 5 } & -0.221 & 0.049 & 0.001 \\
\hline
\end{tabular}

Based on Table 4 information, it can be stated that there is a significant negative relationship between organizational justice and deviant workplace behavior of the university staff at $99 \%$ confidence interval. In other words, as organizational justice increases, staff's inclination to deviant workplace behavior decreases.

Question 2: Is there any significant relationship between deviant workplace behaviors and staff development?

Table (5) correlation between staff development and deviant work behavior

\begin{tabular}{|r||l|l|l|}
\hline \multicolumn{5}{|c|}{ Deviant work behavior } \\
\hline \hline $\begin{array}{r}\text { Staff } \\
\text { development }\end{array}$ & $\begin{array}{l}\text { Pierson } \\
\text { value }\end{array}$ & $\mathrm{R}^{2}$ & sig \\
\cline { 2 - 5 } & -0324 & 0.105 & 0.001 \\
\hline
\end{tabular}


Based on the findings shown in Table 5, it can be said that there is a significant negative relationship between deviant workplace behavior and staff development at $99 \%$ confidence interval. That is to say, as the staff development in a university is stronger, staff's inclination to deviant workplace behavior will decrease.

Multivariate analysis and second-time test of the research hypotheses

In this section, in order to clarify on the effect size of each of the independent variables on the dependent variable in the theoretical model, the results of regression analysis and analysis path of the data will be provided. In multivariate regression analysis, the effect size of each independent variable on the dependent variable is calculated regardless of their priority. Moreover, through analysis path method, the effect size of each independent variable on the dependent variable is measured along with consideration of their priority.

Model processing and analysis through multivariate regression analysis

To analyze and explain the multivariate regression and to attain the regression model of the deviant workplace behavior, we should first specify the variables that are to be fed into the regression formula. To this end, all independent variable have been chosen through stepwise method and have been used in a regression formula to analyze the theoretical model and achieve the final formula.

Examining the regression model by using the main variables

Table 6 illustrates the multivariate regression model which is used to specify the deviant workplace behavior. Moreover, Table 7 delineates the regression analysis indices and statistics. 
Table (6) multivariate regression model for deviant work behavior

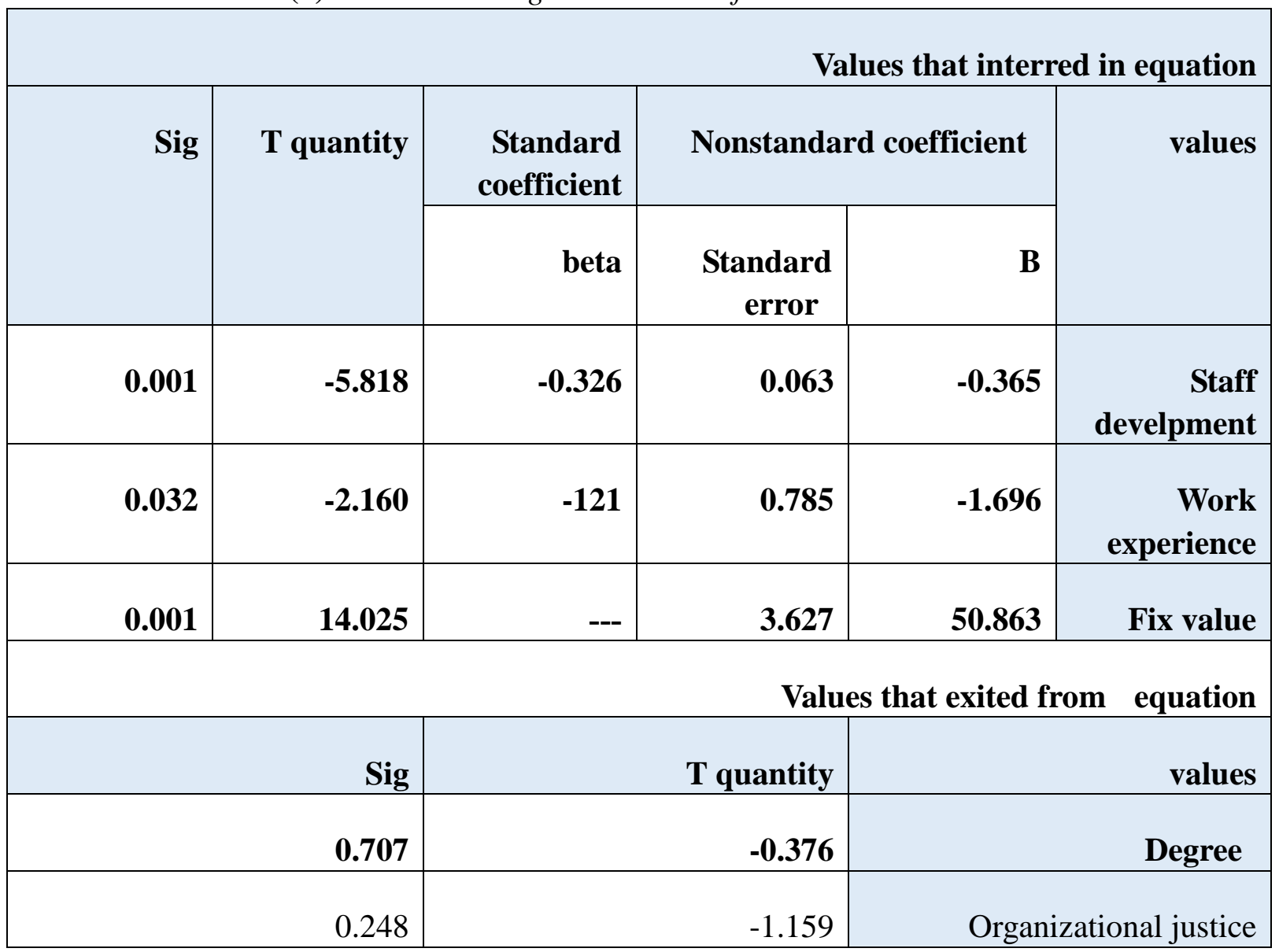

Table (7) indices and statistics of regression analysis for deviant work behavior

\begin{tabular}{||r||c||}
\hline $\begin{array}{r}\text { multiple correlation } \\
\text { coefficient }\end{array}$ & $\mathbf{0 . 3 6 5}$ \\
\hline \hline $\begin{array}{r}\text { Coefficient of } \\
\text { Determination }\end{array}$ & $\mathbf{0 . 1 3 3}$ \\
\hline \hline $\begin{array}{r}\text { Adjusted } \\
\text { Coefficient of } \\
\text { Determination }\end{array}$ & $\mathbf{0 . 1 2 7}$ \\
\hline \hline Standard error & $\mathbf{1 4 . 7 9 7}$ \\
\hline \hline
\end{tabular}

As it can be seen in Table 6, Multiple Correlation R (M.R) and R-Square $\left(\mathrm{R}^{2}\right)$ equal 0.365 and 0.133 , respectively. Moreover, the modified $\mathrm{R}^{2}$ comes to 0.127 , which suggests that nearly 13 percent of the variance and changes in the deviant workplace behavior can be explained by means of the foregoing formula variables. With regard to the fact that Stepwise procedure has been used in the foregoing regression analysis, it is the most explanatory variable that should be entered into the regression model, and then the other variables with higher effects on the dependent variable are successively put into the formula. The statistics 
offered in Table 7 suggest that the staff development variable (beta $=-0.326$ ) affects the deviant workplace behavior more than any other independent variable. Besides, the direction of this effect is negative and reverse, which shows that as the staff development value is greater, the inclination to deviant workplace behavior will be lower. Then, in order to examine the relationship between independent variables, we remove the deviant workplace behavior rate from the previous formula, and enter the independent variables - which have been effective on the deviant workplace behavior - into the new formula as the dependent variables, according to their effect size in the regression formula. As a result, the initial diagram of the path of the factors affecting the deviant workplace behavior was obtained (Figure 1), which is based on the effect size (beta).

Figure 1- The initial diagram of the factors affecting the deviant workplace behavior

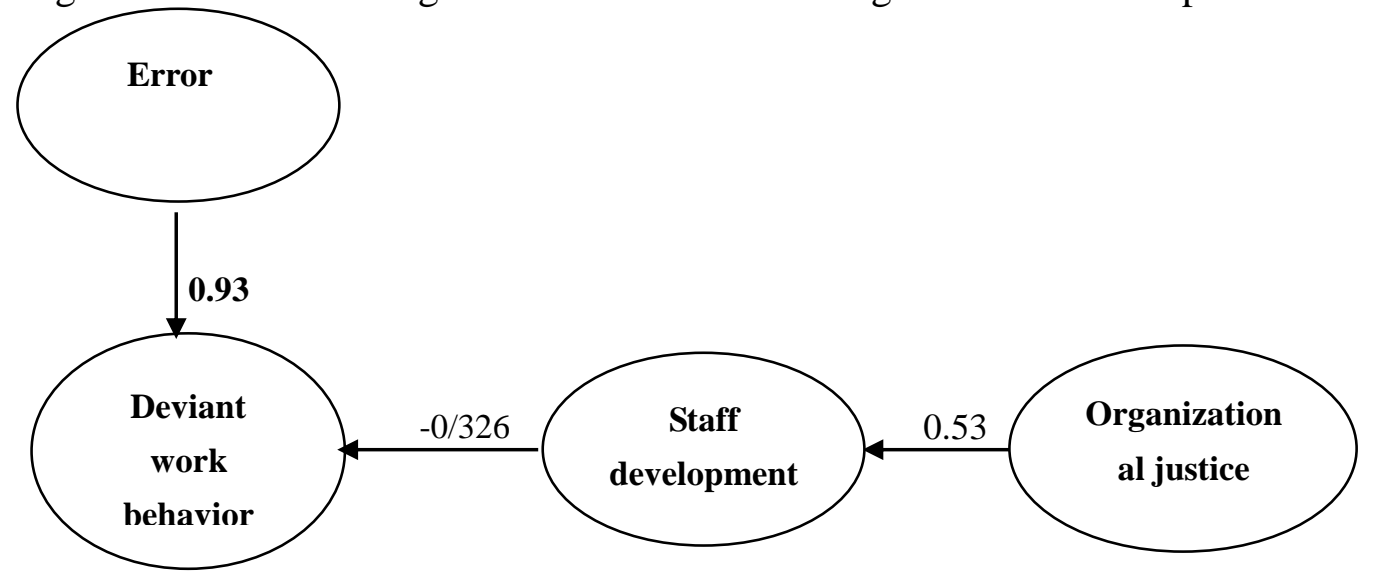

The results of the multiple regression analysis of the foregoing variables can be standardized and mathematically rewritten as following:

Table (8)The effect of independent variables on the deviant work behavior in an initial model

\begin{tabular}{|r||r||r||r||}
\hline Variable & direct effect & Non $\begin{array}{r}\text { direct } \\
\text { effect }\end{array}$ & $\begin{array}{r}\text { Total } \\
\text { effect }\end{array}$ \\
\hline \hline Staff development & -0.326 & ----- & -0.326 \\
\hline \hline Organizational justice & ------ & -0.175 & -0.175 \\
\hline
\end{tabular}

The initial results of the regression analysis suggests the direct effect of the staff development variable and the indirect affect of the organizational justice on the deviant workplace behavior. The biggest effect on the deviant workplace behavior comes from the staff development variable with the beta value of -0.326 , and then, from the organizational justice variable with the beta value of -.0175.

Due to the presence of multiple factors in the structure of the main variables, now we enter the comprising factors of the independent variables into the regression model to examine it more carefully. Therefore, instead of the staff development variable, the six factors of "training improvement, team work, organizational skills, carrier path, interpersonal relationships, and communications" are included, and instead of the organizational justice 
variable, the three factors of "interactional, distributive, and procedural justice" are entered into the model along with job experience and educational degree. As a result, the final diagram of the path of the factors affecting the deviant workplace behavior is obtained in Figure 2, which is based on the effect size (beta).

Figure 2-The final diagram of the factors affecting the deviant workplace behavior

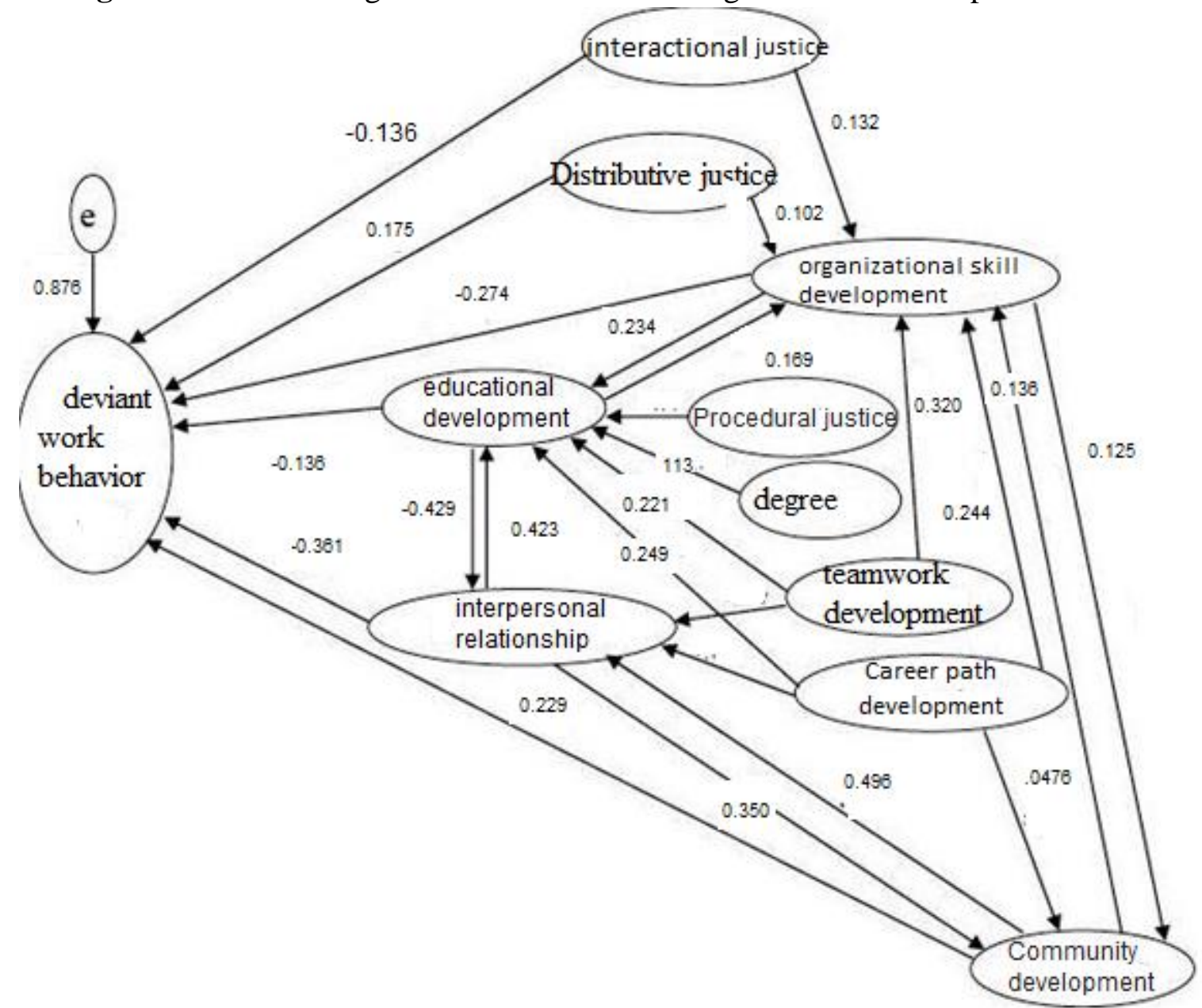

The results of the multiple regression analysis of the foregoing variables can be standardized and mathematically rewritten as following:

Deviant workplace behavior $=0.175$ (distributive justice) - 0.136 (interpersonal justice) 0.361 (developing interpersonal relationships) - 0.274 (developing organizational skills) 0.213 (developing training) +0.229 (developing communications) +0.876

Considering the final causal model in Figure 2, the following points are revealed.

The variable developing interpersonal relationships has a total effect size of -0.656 , and so, is the most powerful variable in specifying the variance of the variable deviant workplace behavior. The next variables are developing the organizational skill and team work (with total effect sizes of -0.267 and -0.226 , respectively) which have a negative relationship with the variable deviant workplace behavior. This means that as the interpersonal relationship, organizational skills, and team work develops more, the inclination of the staff to deviant workplace behavior decreases, and vice versa. On the other hand, the educational degree and 
procedural justice has the lowest total effect ( -0.016 and -0.019 , respectively). This suggests that these variables are not so important when compared with the other variables entered into the regression model, and enjoy lower explanatory power than other variables. Nonetheless, these two variables have a negative relationship with the deviant workplace behavior; that is, as the procedural justice and educational degree of the staff are higher, their inclination to deviant workplace behavior will be lower.

\section{Conclusion}

The results of the present study revealed that the rate of committing deviant workplace behavior in university has been very low (1.5 to 5, on average). Besides, from among the four types of deviant workplace behavior, the highest rate of committing is witnessed in procedural deviation and the least one is seen in the political deviation. Financial deviation comes second in the list, while interpersonal deviation follows it. The university workplace can well justify these findings. First, most of the university staff have had a university degree. Second, they were working in a cultural and educational environment. And third, thy deal with clients who know their rights. Therefore, it is clear that the deviant workplace behavior would rarely emerge in such an environment. The rate of committing the deviant workplace behaviors in the present research population is fairly lower than that of other communities and workplaces. However, if we consider the ideals and public expectations of a university, then this low rate of committing the deviant workplace behaviors will be significant. Indeed, this lower rate should not bar it from receiving due consideration. Nonetheless, the finding that the procedural and financial deviations have been more than interpersonal and political deviations might be explained through a look at the subscales of the deviant workplace behaviors. Under-activity and carelessness in performing the duties comprise much of the procedural deviation value, while carelessness in using the resources and assets has had the highest rate of occurrence in the financial deviation factor. The main justification for under-activity and carelessness in performing the duties is that the staff don't consider their wage and bonuses congruent with the amount of work they are expected to do. In this regard, the staff compare their own job status with those of the other jobs out of the university. In their eyes, other factions of the society, especially liberal workers, with lower capabilities and less work time, earn more than the university employees. Consequently, they unconsciously compensate for this lack of compatibility through under-activity and carelessness. The careless use of the resources and assets can be allocated to the erroneous consumption culture which is common in Iran. People do not consume their own resources and assets properly, and so, they behave the same with regard to the resources and assets of the university.

The findings also suggested that there is a negative yet significant relationship between deviant workplace behavior and staff development (Table 5). This finding is congruent with conclusions made by McKenzie et al (2012). Professional development or non-development staff development is one of the main factors affecting the inclination of an organization's staff to deviant behavior (Georji and Jozef, 2003). Huber (2000) considers the importance of staff development in that the human resources development leads to cultivating an organizational culture in a way that the job and the workplace become interesting and consequently, the organization chooses the methods that lead to the satisfaction of the staff and the clients (Noe, 2008). Professional development of the staff is a constant process which leads to 
improvement in staff's performance regarding the educational and citizenship standards (Taheri, 2011).

Moreover, the findings showed a negative yet significant relationship between staff's job experience and the deviant workplace behavior (Table 6). This finding is compatible with conclusions made by Baghbannia and Khemrnia (2013) and Maccardli (2007). One of the officials of the Iranian Ministry of Education pointed out in the interview that the new staff with little job experience do not have enough information and a true understanding of the official bylaws and rules and regulations in the universities, and consequently, unconsciously commit violations which lead to oral and written warnings. Moreover, employees with more job experience possess higher organizational loyalty than those with little experience (Robins, 2010). The former group's feelings of responsibility and possession toward their respective organization urge them to object to the deviant workplace behaviors.

Furthermore, the findings of the study suggest that there is a negative, significant relationship between deviant workplace behavior and organizational justice (Table 4). That is to say, as the organizational justice increases, the rate of deviant workplace behaviors decreases. This finding is in line with those of Maccardli (2007), Radmand and Salmani (2009), and Golparvar et al (2012). The staff's perceived justice in an organization has a direct relationship with deviant workplace behavior occurrence. Besides, other variables such as type of the organization, its field of activity, and the personal features of the staff affect this relationship. Three theoretical models clearly illustrate how the just and unjust behaviors affect the deviant behavior. The first model, which is based on utilitarian viewpoint, demonstrates that unjust behaviors in economic issues and the staff's wages would ruin their motivation to perform their duties properly. The second model is based on a social and communicative viewpoint, which states that if an individual's social status and personality is not respected in an organization, he/she will try to compensate for it through other ways. The last model is based on the ethical viewpoint, which expresses that if an organization do not observe the ethical principles properly and do not behave fairly, the staff's viewpoint to the organization will be negative and they will try to retaliate (Maccardli, 2007). Employees evaluate the organizational justice based on the results, processes, and interactions, and if they conclude that the organizational behaviors are unjust, then they will develop negative attitudes and feelings toward the organization and will react through objection, dissatisfaction, anger, and retaliatory behaviors (Greenberg, 1998). According the two equity theory, employees compare their contribution and abilities with their accomplishments and received rewards. If they conclude that their accomplishments are less than their contribution and abilities, then there would be a higher chance that they would try to get even. Moreover, employees compare themselves with other staff and then react according to their conclusions (Hosseinzadeh \& Naseri, 2008).

With regard to the present research findings, several suggestions can be offered. First, programs for staff development might be included in the university development programs, where staff development should be considered as an approach to decrease the deviant and harmful workplace behaviors. Second, the staff's belief regarding unjust wages and bonuses should be examined, and in case it is true, the wages and bonuses should be modified, and if it does not come to be true, some programs might be held to change the staff's attitude and 
perception so that they do not aspire to compensate their perceived injustice through under-activity and carelessness. Third, the universities might hold training workshops to inform the staff properly and promptly about the bylaws, circulars, and rules and regulations related to workplace violations, and acquaint the newly recruited staff with the challenges and consequences of the deviant workplace behaviors. At the end, future research projects can be focused on other applied studies regarding the effects of organizational justice, national culture, and professional ethics on the deviant workplace behaviors.

\section{Reference}

Alageband, A.(2010).Sociology of education. Ravan publication, Tehran.

Anselm ,S. Juliet, C.(2006).principle of qualitative research method. Translate by biuk mohammadi. center of humanist and cultural research .Tehran

Appelbaum, S.H., Deguire, K.J. and Lay, M. (2009), “The relationship of ethical climate to deviant workplace behavior", Corporate Governance, Vol. 5 No. 4, pp. 43-56.

Bennett, R. J., \& Robinson, S. L. (2003). The past, present, and future of workplace deviance research (Ed.), Organizational behavior: The state of the science, Second Edition: 247-281.

Blau.J \& Andersson, B. 2005. Personality, affect, and behavior in groups. Journal of Applied Psychology, 75:107-116.

CA: Sage Publications

Chory-Assad, R. M. \& Paulsel, M. L. 2004. Classroom justice: Student aggression and resistance as reactions to perceived unfairness. Communication Education, 53: 253-73.

citizenship behaviours: do fairness perceptions influence employee citizenship. Journal of Applied Psychology, 76 (6): 45-55.

Clíodhna MacKenzie Thomas N. Garavan., Ronan Carbery(2012) Dysfunctional Behavior in Organisations: Can HRD reduce the impact of dysfunctional. Journal of Applied Psychology, 76

Creswell, J. W. (2003). Research design: qualitative, quantitative, and mixed method approaches. Thousand Oaks, CA: Sage.

David,G and Adler.B.(2009). Personality, affect, and behavior in groups revisited: Comment

Ferris, Wendi J.; Brown, Jeffrey A.; Heller, Paul M. 2009. "Be Nice and Fair or Else:Understanding Reasons for Employees' Deviant Behaviors", Journal of Management Development. 26/2:117-131

Galperin, Bella L.; Burke, Ronald J. 2006. "Uncovering the Relationship Between Interactive Effects of Personality and Perception of the Work Situation on Workplace Deviance," Journal of Applied Psychology. 89/4:599-609

Galperin, Bella L.; Burke, Ronald J. 2006. "Uncovering the Relationship Between Interactive Effects of Personality and Perception of the Work Situation on Workplace Deviance," Journal of Applied Psychology. 89/4:599-609

Golipoor,A. , poorezzat,A. (2009).Organizational justice and its three dimensions .Journal of marketing .vol 133 , pp 117-125

Golparvar,M. , Nadi,M.(2011).Mediator roll of organizational loyalty in relationship between job morality and deviant work behavior. Journal of moral in science and technology .voll1, pp 43-53.

Greenberg, J. 1998. The quest for justice on the job: essays and experiments. Thousand Oaks, 
Hooman, H.(2007). Psychological and Educational measurement .Parsa publication .Tehran.

Journal of Applied Psychology, 78: 798-804.

justice. In G. Ferris (Ed.), Research in personnel and human resources management, vol 131,pp 140-133

Lamperz Carrington, (2004),"Professional development for inclusive schooling", International Journal of Educational Management, Vol. 16 Iss: 5 pp. 239 - 247

Mccardle. G. J.(2007). The role of organizational structure, powerlessness, and information salience . Dissertation in in the Department of Management in the College of Business Administration at the University of Central Florida Orlando, Florida

Meredith, D. , Gall, W. R. , Borg, P(1996).Educational research :an introduction .Longman publisher, USA C1996, $6^{\text {th }}$ ed.

Moorman R.H. 1991. Relationship between organizational justice and organizational

on aggregation, level of analysis, and a recent application of within and between analysis.

Parker, P.J \&Kohlmeyer, J.M(2005). "Organizational Justice and Turnover in Public Accounting Firms: a Research Note”, Accounting, Organizations and Society, Vol. 30, pp:357-369

Peterson DK (2002). Deviant workplace behavior and the organizations ethical climate. Journal of Business and Psychology 17(1): 47-61

Robinson, S. L., \& Bennett, R. J. 1997. Workplace deviance: Its definition, its manifestations,

Rupp, D. E., Mohler, C. J., \& Schminke, M. 2001. Three roads to organizational

saif, A.(2011).building Instruments to measure research variables in education and psychology . Tehran, Didar publication .

Salmani, D.,Radmand, M.(2009).the roll of organizational factor and management in creating deviant work place behavior .journal of public management,vol12, pp55-68

Shahpasand,M. , Hejazi,Y. ,Rezvanfar,A. , Saebi,M.(2006).Study of professional development in Jahad keshavarzi education complex .journal of research and building, voll184,pp74-172.

Shokrkon ,H. , Neami, A.(2001).Study of relation between organizational justice and citizenship behavior.Journal of education and phycology. Chamran university ,Iran , voll92, pp1-22

Taheri, M.(2011).Model of professional development in teacher training center. PhD teases in Faculty of education and psychology, Shahid Beheshti university, Tehran, Iran.

Zareh, f.(2011).the role of organizational justice in building organizational commitment .quarterly journal of human resource, vol8, p35-41. 